\title{
Role of janus kinase inhibitors in the treatment of alopecia areata
}

This article was published in the following Dove Press journal:

Drug Design, Development and Therapy

\section{Korn Triyangkulsri \\ Poonkiat Suchonwanit}

Division of Dermatology, Department of Medicine, Faculty of Medicine, Ramathibodi Hospital, Mahidol

University, Bangkok, Thailand
Correspondence: Poonkiat Suchonwanit Division of Dermatology, Department of Medicine, Faculty of Medicine, Ramathibodi Hospital, Mahidol University, 270, Rama VI Road, ThungPhaya Thai, Ratchathewi, Bangkok 10400, Thailand Tel +66220 I I I I I

Fax +662201 1211

Email poonkiat@hotmail.com

\begin{abstract}
Alopecia areata (AA) is a common hair loss disorder worldwide with characteristic exclamation mark hairs. Although AA is self-limited, it can last for several months or even years in some patients. Currently, there is no US Food and Drug Administration-approved treatment for AA. Many off-label treatments are available but with limited efficacy. Through a better understanding of molecular biology, many targeted therapies have emerged as new alternatives for various autoimmune diseases. Various janus kinase (JAK) and signal transducer and activator of transcription (STAT) proteins form signaling pathways, which transmit extracellular cytokine signals to the nucleus and induce DNA transcriptions. By inhibiting JAK, T-cell-mediated inflammatory responses are suppressed. Increasing evidence suggests that JAK inhibitors (JAKis) are effective in the treatment of many autoimmune diseases, including AA. Among these, several studies on tofacitinib, ruxolitinib, and baricitinib in AA had been published, demonstrating promising outcomes of these agents. Unlike oral formulations, efficacy of topical forms of tofacitinib and ruxolitinib reported in these studies is still unsatisfactory and requires improvement. This review aims to summarize evidence of the efficacy and safety of JAKis in the treatment of AA.
\end{abstract}

Keywords: baricitinib, JAK, JAK inhibitors, JAK-STAT pathway, ruxolitinib, tofacitinib

\section{Introduction}

Alopecia areata (AA) is an autoimmune disease characterized by a nonscarring patch or patches of hair loss with characteristic exclamation mark hairs. AA is a relatively common disease with a worldwide prevalence of $0.1 \%-0.2 \% .^{1}$ It is found to be associated with atopic dermatitis, ${ }^{2}$ vitiligo, systemic lupus erythematosus, and autoimmune thyroid diseases. ${ }^{3,4}$ Other than autoimmune factors, AA is thought to be driven by genetic predisposition. There have been several studies suggesting genetic background with familial incidence of 7\%-18\% depending on the type of AA. ${ }^{5,6}$ Evidence, of its prevalence in the population of about $2 \%$, concordance in twins, a Gaussian distribution of severity, a 10-fold increased risk of first-degree relatives of affected individuals, and the aggregation of affected individuals in families with no clear Mendelian pattern of inheritance, suggests that AA fits a complex or multifactorial genetic pattern. ${ }^{7}$ Furthermore, AA is found to be associated with several human leukocyte antigens, such as DQ3, DR4, DR11, and DQ7. ${ }^{8}$ Currently, there is no United State Food and Drug Administration (FDA)-approved treatment for AA. Many off-label treatments are available but with limited efficacy. Thus, there is still room for new alternatives for the treatment of AA. Increasing evidence suggests that JAK inhibitors (JAKis) are effective in the treatment of AA. This review aims to summarize evidence on the efficacy and safety of JAKis, in the hope of improving the understanding and treatment 
of AA, and to suggest future directions in which JAKis may be promising candidates for the treatment of other hair loss disorders.

\section{Pathogenesis of AA}

Hair follicles are immune-privileged sites with complex and intricate structures to maintain their immunity against the body immune system. The key features of an immuneprivileged site are low major histocompatibility complex (MHC) class I and II expression and well-suppressed natural killer (NK) cells. ${ }^{9}$ Disruption of the system, namely upregulation of MHC class I or UL16-binding protein 3 (ULBP3) molecules ${ }^{10}$ or defect in NK cell inhibition or containment, results in loss of immune privilege and ultimately causes AA. ${ }^{11}$ ULBP3 was identified as an important factor in AA pathogenesis by various genome-wide association studies. Its overexpression leads to the attack of cytotoxic cluster of differentiation 8-positive (CD8+) NK group 2D-positive (NKG2D+) T cells to the hair follicles. ${ }^{12,13}$ Hair follicles that lose their immune privilege during anagen phase become the target of CD8+ T cells and NKG2D+ cells. ${ }^{14}$ This hypothesis is supported by the findings of CD8+ T cells and NKG2D+ cells around the peribulbar area of the affected hair follicles. ${ }^{11,15}$ Concurrently, marked interferon (IFN)- $\gamma$ response and upregulation of several $\gamma$-chain $\left(\gamma_{c}\right)$ cytokines, including interleukin (IL)-2, IL-7, IL-15, and IL-21, and IFN- $\gamma$ elements, promote activation and survival of IFN- $\gamma$-producing CD $8+N K G 2 D+T$ cells and contribute to immune privilege collapse of hair follicles. ${ }^{10}$ These events ultimately lead to hair follicle dystrophy and accelerate hair follicles into catagen phase. ${ }^{16}$

\section{JAK-STAT signaling pathway and its role in AA}

JAK-STAT signaling pathway consists mainly of three components: receptor, janus kinase (JAK), and signal transducer and activator of transcription (STAT) (Figure 1). The receptor, on the cell surface, binds to specific ligands, such as IFNs, ILs, and various other cytokines and hormones. JAK is a member of tyrosine kinase family, which consists of JAK1, JAK2, JAK3, and tyrosine kinase 2 (TYK2). JAK, after receiving signal by the ligands, phosphorylates its own tyrosine component to activate its kinase

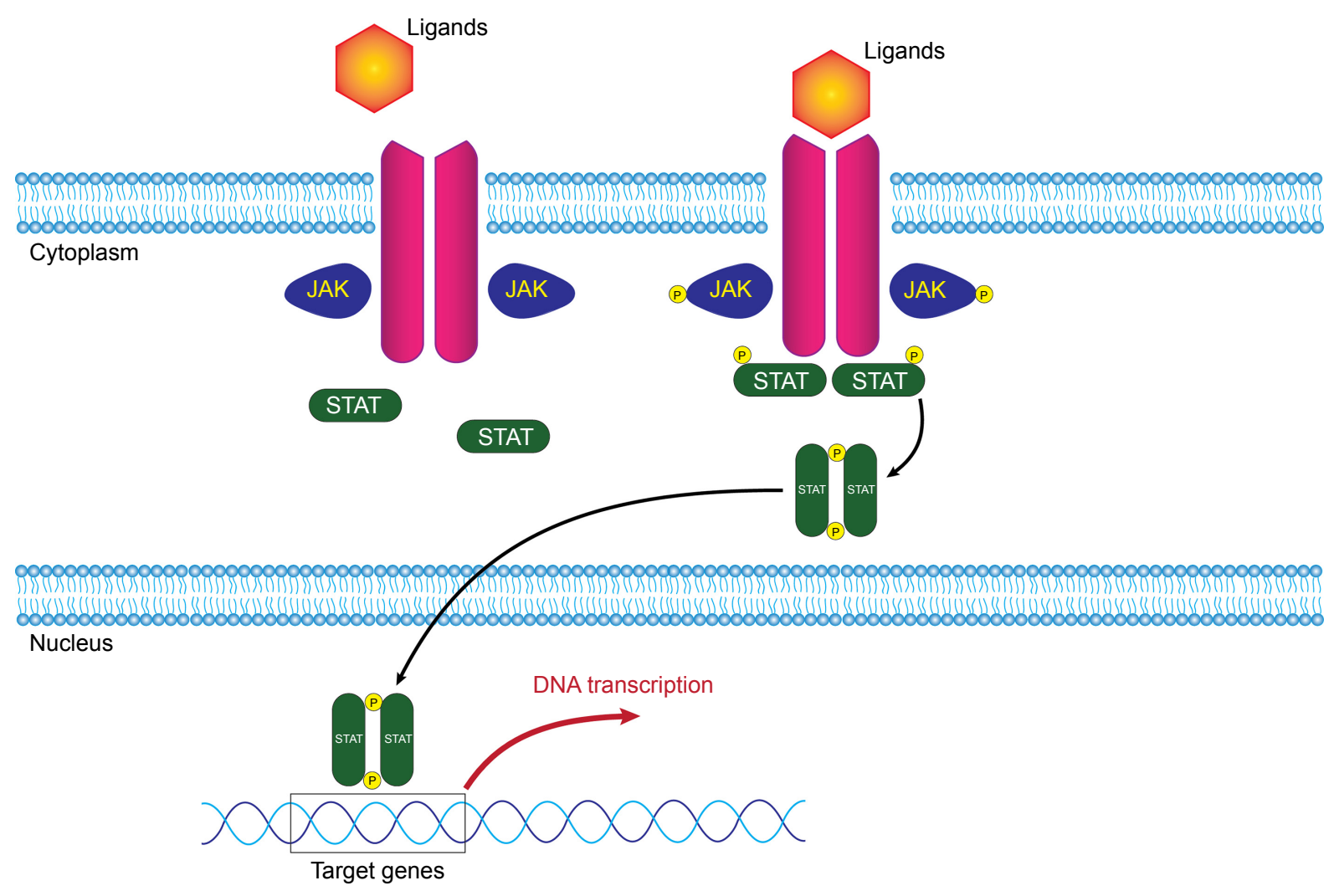

Figure I Illustration of JAK-STAT signaling pathway.

Notes: Specific ligands bind to their corresponding receptors and activate JAK component. JAK phosphorylates its own tyrosine component to activate its kinase function which in turn phosphorylates STAT component. Activated STATs translocate to promote transcription of DNA in the nucleus.

Abbreviations: JAK, janus kinase; STAT, signal transducer and activator of transcription. 
function, which in turn phosphorylates STAT component. Phosphorylation of the STAT component dimerizes and activates STATs. The activated STATs then will, in turn, translocate to the DNA in the nucleus and promote transcription of a specific region of the DNA, leading to gene expression (Figure 1). This fundamental process of gene expression mediates cellular processes through activation of cytokines. Function of the JAK-STAT signaling pathway was first discovered as a pathway for IFN signaling. ${ }^{17-19}$ Subsequently, a large number of cytokines, particularly $\gamma_{c}$ cytokines, have been found to activate the JAK-STAT pathway, leading to a myriad of gene expression. ${ }^{20} \mathrm{JAK}-\mathrm{STAT}$ pathway is vital in maintaining innate and adaptive immunity. Any defect in JAK component results in certain hematologic or immune-related diseases, such as myeloproliferative neoplasms or severe combined immunodeficiency. ${ }^{21,22}$

Given a crucial role that JAK-STAT pathway plays in mediating the CD8+ NKG2D+T cell reaction, which is a component of AA pathogenesis, JAKis seem to be an appealing option for the treatment of AA. Moreover, inhibition of this pathway results in promotion of hair growth cycle, which increases effectiveness of hair loss treatment. ${ }^{10}$ Figure 2 demonstrates the interaction between JAK-STAT pathway, in pathogenesis of AA, and JAKis. Further information regarding the relationship between JAK-STAT pathway and hair growth cycle, as well as JAKis and AA, is discussed in the next sections.

\section{JAK and hair growth cycle}

In terms of hair growth, key genes in the JAK-STAT pathway including Stat $5 A / B$, Stat3, Jak1, Jak3, and Socs $2 / 3$ were highly expressed in catagen and telogen phases but suppressed in early anagen phase. ${ }^{23}$ IL- 6 and oncostatin M (OSM), which signal via JAK-STAT pathway, have been shown to play a role in hair growth regulation. Overexpression of IL-6 in keratinocytes in mice results in hair growth

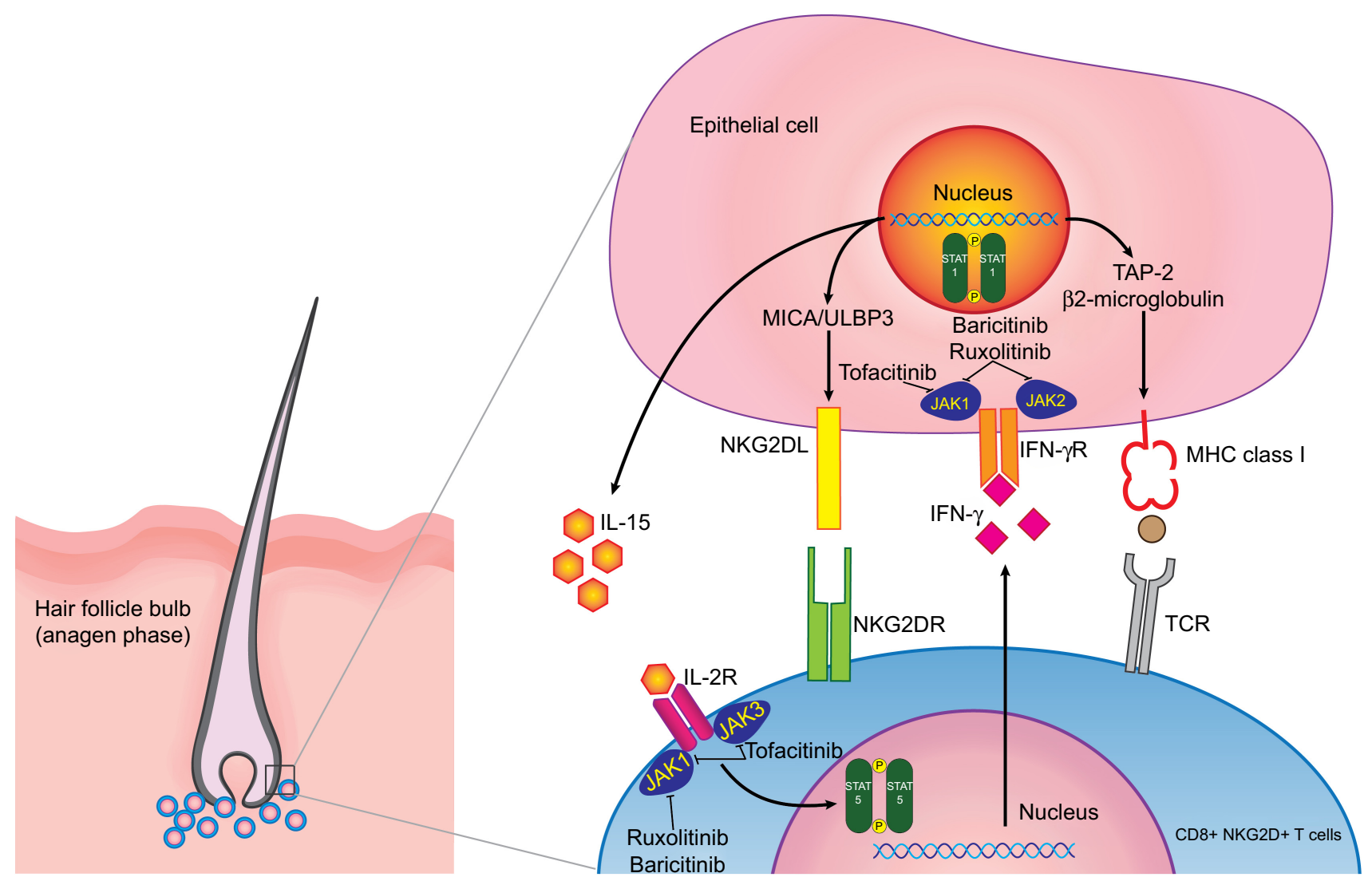

Figure 2 Interaction between follicular epithelial cells and CD8+ NKG2D+T cells.

Notes: CD8+ NKG2D+T cells form immune synapses with follicular epithelial cells and in turn upregulate MHC class I expression through JAKI and JAK2. Concurrently, NKG2D ligands (NKG2DL), such as MICA and ULBP-3, are also upregulated through JAKI and JAK3. Activated CD8+ NKG2D+T cells release IFN- $\gamma$ that binds to its receptor on follicular epithelial cells, causing transition into catagen phase. This also causes follicular epithelial cells to promote the production of IL-I5 through JAKI and JAK2. IL-I5 in turn binds to its receptor on CD8+ T cells and induces JAKI- and JAK3-mediated IFN- $\gamma$ production and ultimately completes the feedback loop. Tofacitinib mainly inhibits JAKI and JAK3, while ruxolitinib predominantly inhibits JAKI and JAK2. Lastly, baricitinib selectively inhibits JAKI and JAK2. These inhibitions interfere with the feedback loop and alleviate AA.

Abbreviations: IFN, interferon; IL, interleukin; JAK, janus kinase; MHC, major histocompatibility complex; NK, natural killer; STAT, signal transducer and activator of transcription; TAP-2, transporter associated with antigen processing-2; TCR, T-cell receptor. 
retardation..$^{24}$ IL-6 is also found to be more prominent in balding dermal papilla compared with nonbalding dermal papilla. The same study also showed that injection of recombinant IL-6 into anagen skin can induce premature onset catagen phase. ${ }^{25}$ Finally, IL-6 and OSM were found to inhibit hair shaft elongation in the human organ culture model. ${ }^{25,26}$ Anagen extension and hair regrowth were found in mice receiving tofacitinib, a JAKi. The study also proved that, after inhibiting JAK-STAT pathway, vascular endothelial growth factor is upregulated, resulting in angiogenesis. This suggests the role of JAK in hair growth. ${ }^{27}$ Harel et al showed that inhibiting JAK-STAT pathway promotes hair growth by stimulating the activation and/or proliferation of hair follicle stem cells and other unknown mechanisms. ${ }^{23}$ It was also shown that suppression of JAK signaling activates an antiquiescence signal during telogen phase and accelerates reentry into anagen phase in mice. However, no study was able to establish the same effect on human hair follicles.

\section{JAKis and AA}

Over the past few years, various JAKis have been reported to have promising efficacy in various autoimmune disorders, such as rheumatoid arthritis ${ }^{28}$ and psoriasis, ${ }^{29}$ and myeloproliferative disorders, such as myelofibrosis or polycythemia vera. ${ }^{30}$ In the same manner, AA was also found to be responsive to JAKi treatment. Several studies had helped bring light to the mechanism of JAKis in stimulating hair growth in AA. Overexpression of JAK 3 and, to a lesser extent, JAK1 and JAK2 was observed in skin biopsy specimens of patients with AA. ${ }^{31}$ In terms of hair growth in AA, a two-step mechanism needs to be fulfilled. ${ }^{32}$ First, T-cell-mediated immune response on the hair follicle must be terminated. Xing et al demonstrated that the involvement of $\gamma_{c}$ cytokine and receptor family members in AA and JAKis blocked the downstream signal of such cytokines. ${ }^{10}$ JAKis also disrupt the production of inflammatory Thelper (Th) 17 cells and Th1 and Th2 differentiation (Figure 2). ${ }^{33}$ Second, anagen phase must be reinstated. Restoration of anagen phase of the hair follicle by JAK inhibition has been discussed previously in this article (see JAK and hair growth cycle). Currently, there are three medications that have been reported in various trials for the treatment of AA. Each of which is reviewed in this article.

\section{Tofacitinib}

Tofacitinib (CP-690,550, formerly tasocitinib) is the first of the JAKi family. Its chemical formula is $\mathrm{C}_{16} \mathrm{H}_{20} \mathrm{~N}_{6} \mathrm{O}$ (Figure 3) ${ }^{34}$ It selectively inhibits JAK1 1 - and JAK3-dependent STAT activation over JAK2, with minimal effects on TYK2 pathway. ${ }^{35}$ Tofacitinib blocks STAT phosphorylation induced

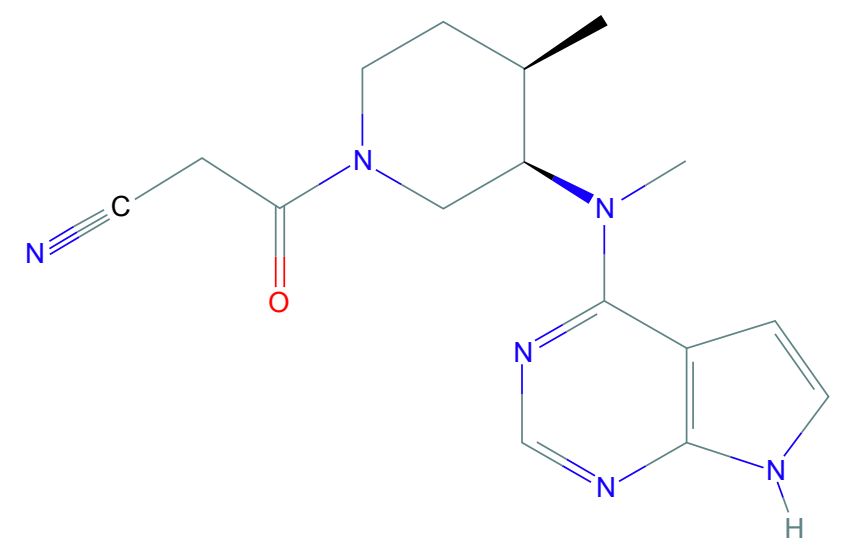

Figure 3 Tofacitinib.

by IFN- $\gamma$, IL-2, IL4, IL-7, IL-15, and IL-21, which clearly affects the signaling pathway downstream of JAK1- and JAK3-dependent $\gamma_{c}$ receptors in both mice and humans. IL-12 signaling, which depends on JAK2 and TYK2, is blocked for STAT1 activation but only mildly suppressed for STAT4. ${ }^{36}$ Additionally, anti-inflammatory effects of tofacitinib have also been described in some studies. ${ }^{27,33,36}$

Efficacy of tofacitinib in AA was first reported by Craiglow and King in 2014. ${ }^{37}$ A 25 -year-old male patient with psoriasis and, coincidentally, alopecia universalis (AU) was treated with oral tofacitinib, showing improvement in both psoriasis and AU. Full regrowth of hair at all body sites was observed after 8 months of therapy with $15 \mathrm{mg}$ per day of oral tofacitinib. Since then, several clinical studies on adolescent and adult patients have been published (Table 1). ${ }^{37-58}$ These cases were mostly diagnosed with AU and some with AA. Most of the cases were also unresponsive to their previous treatments, including various regimens of corticosteroid, cyclosporine, and/or methotrexate. In a 38-year-old male with AU and nail dystrophy associated with AA, total hair regrowth and normalization of nails were observed after 10 months of treatment with oral tofacitinib $5 \mathrm{mg}$ twice daily. ${ }^{43} \mathrm{~A}$ case report of a 40 -year-old woman with moderate-to-severe AA demonstrated almost complete regrowth of hair after 4 months of treatment with oral tofacitinib $5 \mathrm{mg}$ twice daily. The same study also found that initial elevation of CXCL10 (an IFN-induced chemokine), IFN, and cytotoxic $\mathrm{T}$ lymphocyte signatures was decreased after 4 weeks of treatment. However, cessation of tofacitinib resulted in near-complete hair loss. ${ }^{44}$

Several retrospective studies have also been published. In the largest study conducted by Liu et al, ${ }^{39}$ efficacy of oral tofacitinib $5 \mathrm{mg}$ or more twice daily as monotherapy or as combination therapy with prednisone was evaluated in 90 patients with AA and its variants. Patients aged 


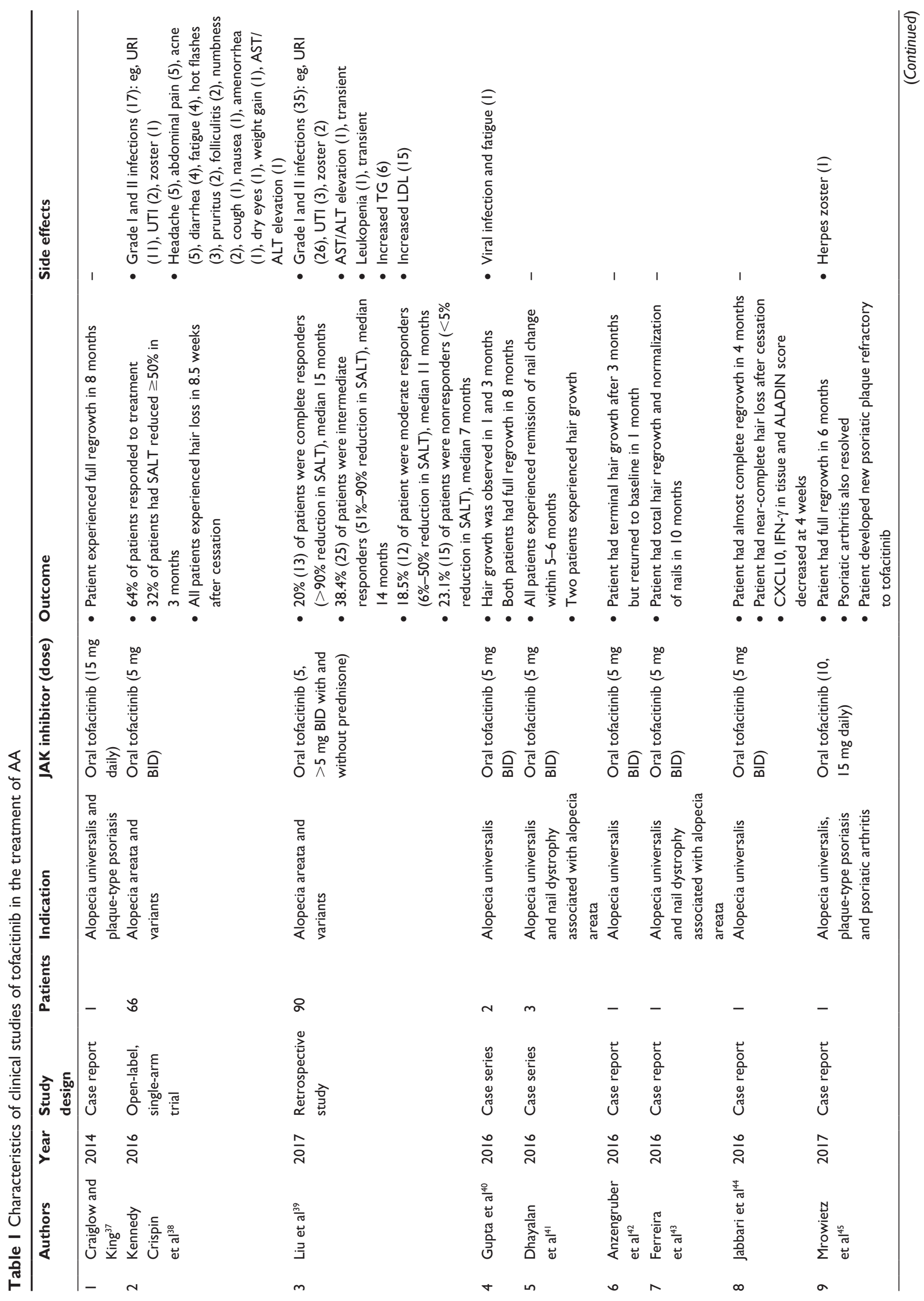




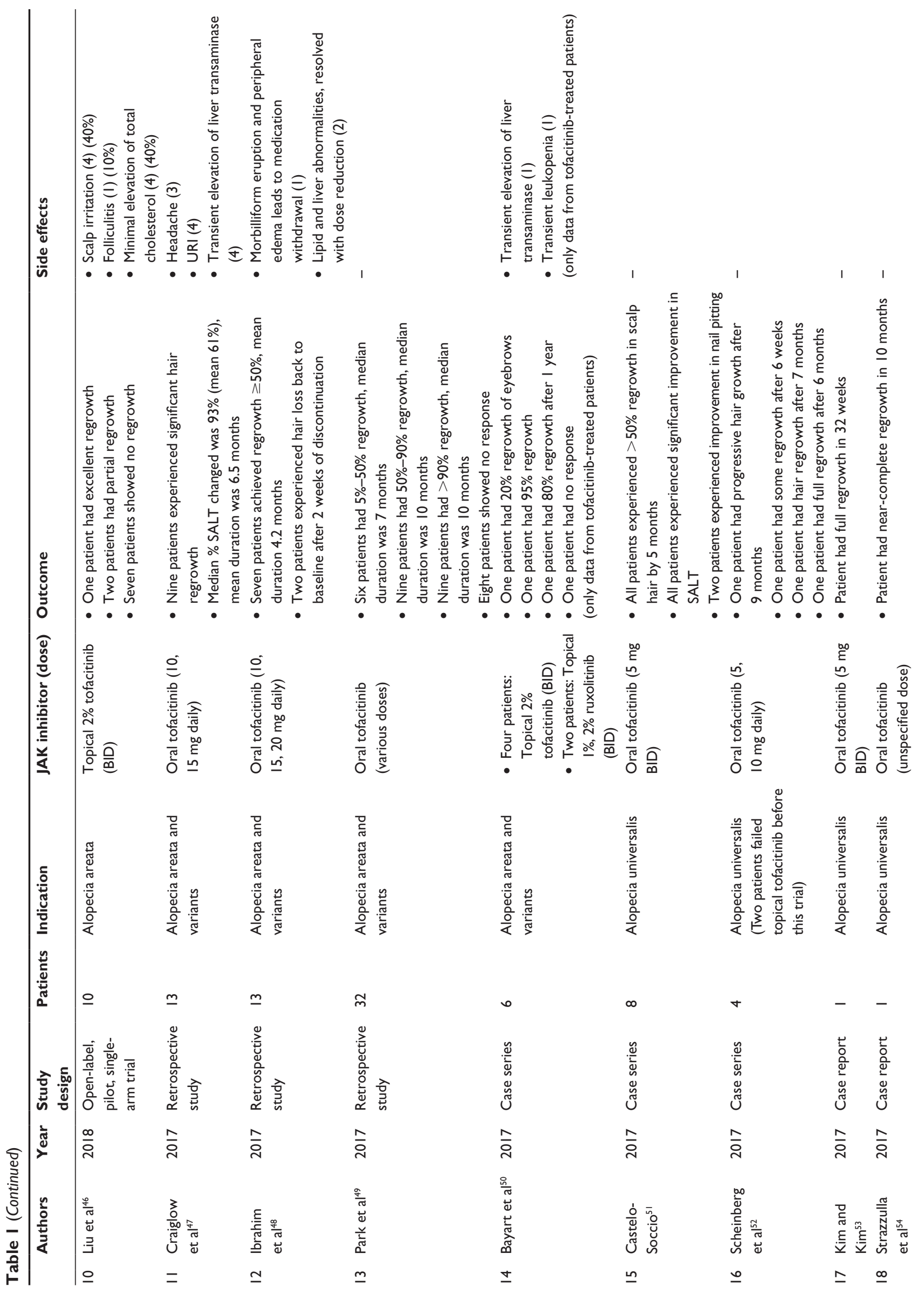




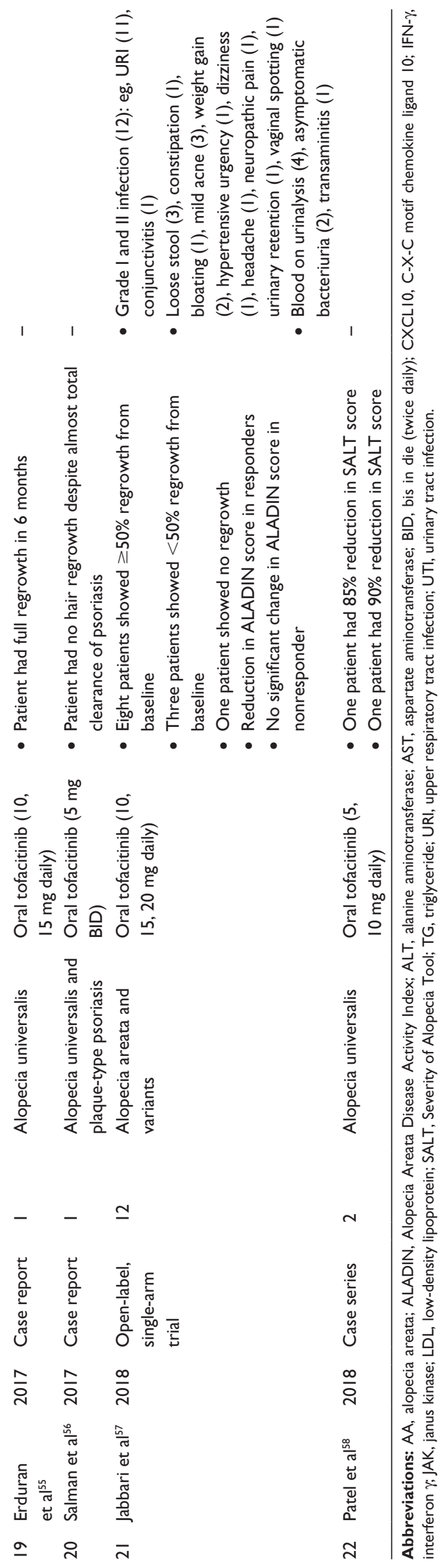

18-70 years old were evaluated for Severity of Alopecia Tool (SALT) score at baseline and after various treatment durations (4-12 months). Sixty-five patients were identified as potential responders (patients whose current episode of alopecia totalis [AT] or AU was 10 years or less or patients with AA). Of the potential responders, 13 patients $(20 \%)$ were complete responders having $>90 \%$ reduction in SALT. Twenty-five (38.4\%) patients were intermediate responders (51\%-90\% reduction in SALT), 12 (18.5\%) were moderate responders $(6 \%-50 \%$ reduction in SALT), and 15 (23.1\%) were nonresponders ( $\leq 5 \%$ reduction in SALT).

In an open-label, single-arm study, 66 patients with AA who had $>50 \%$ hair loss, AT, or AU were given oral tofacitinib $5 \mathrm{mg}$ twice daily for 3 months. Outcome was evaluated from regrowth of scalp hair assessed by SALT, duration of hair growth after completion of therapy, and disease transcriptome. Of 66 treated subjects, $32 \%$ of patients had $\geq 50 \%$ reduction in SALT. AA and ophiasis subtypes were more responsive than AT or AU. Shorter duration and histologic peribulbar inflammation of pretreated scalp biopsies were associated with improvement in SALT..$^{38}$ Recently, in 2018, another open-label, single-arm study on 12 patients with moderate-to-severe AA, AT, or AU had been published. Each patient was given oral tofacitinib for $10 \mathrm{mg}$ daily for 1 month and the dosage was increased gradually to $15 \mathrm{mg}$ daily and $20 \mathrm{mg}$ daily if the patient did not achieve at least $50 \%$ regrowth of hair from baseline. A full course of treatment was defined as having $\geq 50 \%$ regrowth of hair from baseline for 6-12 months while taking tofacitinib. Patients were then required to stop tofacitinib after completing a full course treatment and reevaluating after 6 months of tofacitinib cessation. Eleven of the 12 patients completed the full course treatment with minimal adverse events. Eight patients experienced $\geq 50 \%$ regrowth of hair from baseline, while three experienced $\leq 50 \%$ regrowth of hair and one experienced no regrowth. ${ }^{57}$

An open-label, single-arm trial and a case series investigated the safety and efficacy of topical tofacitinib in patients with $\mathrm{AA} .{ }^{46}$ In the clinical study, 10 patients with AA were treated with $2 \%$ tofacitinib ointment twice daily. Regrowth of scalp hair was assessed by using SALT; one achieved excellent regrowth, two had partial regrowth, and seven had no regrowth.

In terms of safety, reported side effects include only mild symptoms, grade I and II infections, as well as transient elevation of liver transaminase, and cholesterol level (Table 1). . $8,39,47,48,50,57$ Most of these symptoms or abnormalities were transient and reversible either spontaneously or with discontinuation of tofacitinib. One retrospective study by 
Ibrahim et al reported a patient having morbilliform eruption and peripheral edema leading to cessation of oral tofacitinib. ${ }^{48}$ Information on long-term safety of tofacitinib was indirectly extrapolated from clinical trials in rheumatoid arthritis. Tuberculosis was observed in $10 \mathrm{mg}$ dosage groups (incidence rate 0.5 events $/ 100$ patient-years) but not in $5 \mathrm{mg}$ dosage groups (95\% CI 0.1-0.9). Rate of opportunistic infection other than tuberculosis was low and limited to herpes zoster without visceral involvement or death. ${ }^{59}$ Lung cancer and breast cancer were the most common malignancies that occurred during tofacitinib treatment. The overall rate of occurrence of malignancies, excluding nonmelanoma skin cancer, was 0.939 events/100 patient-years (95\% CI 0.737-1.198). ${ }^{60}$ However, all this information of adverse events must be taken into account that the studied population could be affected by rheumatoid arthritis and its treatment.

\section{Ruxolitinib}

Ruxolitinib (INC424 or INCB018424), a JAKi with chemical structure of $\mathrm{C}_{17} \mathrm{H}_{18} \mathrm{~N}_{6}$ (Figure 4), ${ }^{61}$ is FDA-approved for the treatment of myelofibrosis. ${ }^{62,63}$ It selectively inhibits JAK1 and JAK2 and, to some extent, TYK2. ${ }^{64}$ Other than the effects of JAK-STAT pathway inhibition, ruxolitinib has been shown to have anti-inflammatory effects, which are thought to be due to interruption of the IL-17 signaling axis. ${ }^{65}$ Concurrently, ruxolitinib has been demonstrated to reduce cytokine-induced phosphorylation of STAT3 ${ }^{64,66}$ and levels of circulating inflammatory cytokines such as tumor necrosis factor- $\alpha$ and IL-6 in mice. ${ }^{64}$ Eyelash growth was observed in a patient with hypereosinophilic syndrome after

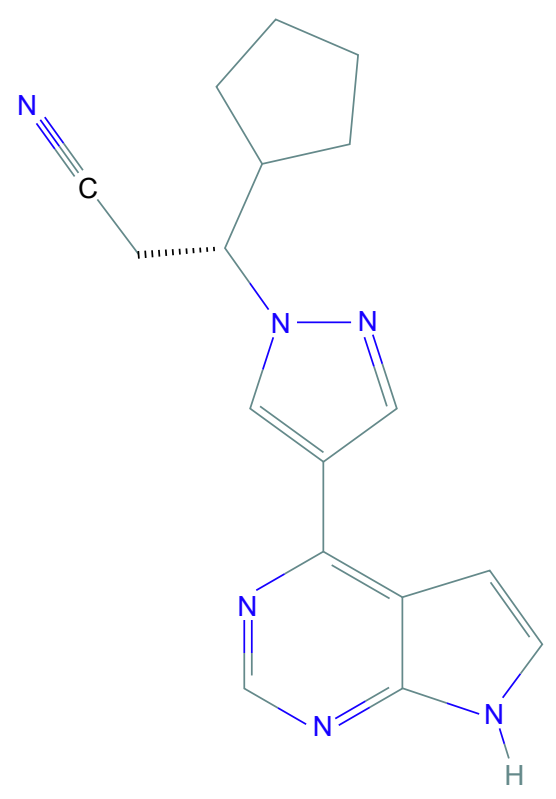

Figure 4 Ruxolitinib. having taken ruxolitinib, but the responsible mechanism was not elucidated. ${ }^{67}$

A number of case reports and one open-label, single-arm trial of ruxolitinib have been published (Table 2). ${ }^{10,50,68-73}$ Concerning oral ruxolitinib, Xing et al, apart from establishing the effects of JAKis in alopecic skin through in vivo study, had reported three cases of AA treated with $20 \mathrm{mg}$ of oral ruxolitinib twice daily. ${ }^{10}$ All three patients experienced near-complete regrowth within 3-5 months. Pieri et al later reported a near-complete hair growth after $15 \mathrm{mg}$ of oral ruxolitinib twice daily was administered to a patient with AU and essential thrombocythemia. ${ }^{68}$

In an open-label, single-arm trial for oral ruxolitinib, 12 patients with moderate-to-severe AA were given $20 \mathrm{mg}$ of oral ruxolitinib twice daily for 3-6 months. The proportion of patients with $50 \%$ or greater hair regrowth from baseline was the primary endpoint. Nine patients $(75 \%)$ had significant hair growth (mean improvement of $92 \%) .^{70}$

Despite promising outcomes in a mouse model reported by Xing et al, unfavorable efficacy of the topical form of ruxolitinib had been demonstrated in three case reports. ${ }^{10}$ Craiglow et al reported a case of $\mathrm{AU}$ treated with $0.6 \%$ ruxolitinib cream. ${ }^{69}$ The patient had near-complete regrowth of eyebrows, but only $10 \%$ growth of scalp hair after 12 weeks. Bayart et al revealed two cases of AU treated with $1 \%$ and $2 \%$ ruxolitinib in liposomal base. ${ }^{50}$ No response was observed in the patient treated with $2 \%$ ruxolitinib, whereas the other receiving $1 \%$ ruxolitinib experienced regrowth of only upper eyelashes but not the eyebrows. Similarly, Deeb and Beach reported no improvement in the patient with AA who underwent the treatment with $0.6 \%$ ruxolitinib cream. ${ }^{72}$

As for the safety issue of ruxolitinib, all clinical studies on AA patients have reported only mild symptoms and grade I or II infection (Table 2). ${ }^{69-71}$ Data from studies on ruxolitinib in myelofibrosis patients show hematologic adverse events mainly dose-related anemia, thrombocytopenia, and neutropenia. These conditions can be explained by the fact that ruxolitinib inhibits JAK2-STAT signaling in normal hematopoiesis. Common nonhematologic adverse events included nonsevere bruising, dizziness, and headache. ${ }^{74}$ Ruxolitinib proved to be noncarcinogenic in the 6-month $\mathrm{Tg}$.rasH2 transgenic mouse model and in a 2-year carcinogenicity study in the rat. Furthermore, there has yet to be any report on ruxolitinib-related malignancy in the literature. ${ }^{66}$

\section{Baricitinib}

Baricitinib (LY3009104 or INCB028050) is a potent selective JAK1 and JAK2 inhibitor with a recognizable degree of JAK3 and various kinase inhibition. Its chemical structure 
Table 2 Characteristics of clinical studies of ruxolitinib and baricitinib in the treatment of AA

\begin{tabular}{|c|c|c|c|c|c|c|c|}
\hline Authors & Year & Study design & Patients & Indication & JAK inhibitor (dose) & Outcome & Side effects \\
\hline I Xing et $\mathrm{al}^{10}$ & 2014 & Case series & 3 & Alopecia areata & $\begin{array}{l}\text { Oral ruxolitinib }(20 \mathrm{mg} \\
\text { BID) }\end{array}$ & $\begin{array}{l}\text { - All patients } \\
\text { experienced near- } \\
\text { complete regrowth } \\
\text { within 3-5 months }\end{array}$ & - \\
\hline 2 Pieri et $a^{68}$ & 2015 & Case report & I & $\begin{array}{l}\text { Alopecia universalis } \\
\text { and essential } \\
\text { thrombocythemia }\end{array}$ & $\begin{array}{l}\text { Oral ruxolitinib (I } 5 \mathrm{mg} \\
\text { BID) }\end{array}$ & $\begin{array}{l}\text { - Patient had near- } \\
\text { complete regrowth } \\
\text { within } 10 \text { months }\end{array}$ & - \\
\hline $\begin{array}{l}3 \text { Craiglow } \\
\text { et al }{ }^{69}\end{array}$ & 2016 & Case report & I & Alopecia universalis & $\begin{array}{l}\text { Topical } 0.6 \% \\
\text { ruxolitinib (BID) }\end{array}$ & $\begin{array}{l}\text { Patient had near- } \\
\text { complete regrowth } \\
\text { of eyebrows and } 10 \% \\
\text { regrowth of scalp hair } \\
\text { in } 12 \text { weeks }\end{array}$ & - Leukopenia (I) \\
\hline $\begin{array}{l}4 \text { Mackay- } \\
\text { Wiggan } \\
\text { et } \mathrm{al}^{70}\end{array}$ & 2016 & $\begin{array}{l}\text { Open-label, } \\
\text { single-arm trial }\end{array}$ & 12 & Alopecia areata & $\begin{array}{l}\text { Oral ruxolitinib }(20 \mathrm{mg} \\
\text { BID) }\end{array}$ & $\begin{array}{l}\text { - Nine patients had } \\
\text { regrowth } \geq 50 \% \\
\text { Nine responders } \\
\text { experienced reduction } \\
\text { of hair loss from } \\
\text { baseline by } 92 \%\end{array}$ & $\begin{array}{l}\text { - } \text { Bacterial skin infection (3) } \\
\text { - URI (9) } \\
\text { - UTI (I) } \\
\text { - } \text { Mild pneumonia (I) } \\
\text { - Postoperative } \\
\text { conjunctival hemorrhage } \\
\text { (I) } \\
\text { - Mild GI symptoms (I) } \\
\text { - Lower hemoglobin: } \\
\text { resolved with dose } \\
\text { reduction (I) }\end{array}$ \\
\hline 5 Bayart et a $\left.\right|^{50}$ & 2017 & Case series & 6 & $\begin{array}{l}\text { Alopecia areata and } \\
\text { variants }\end{array}$ & $\begin{array}{l}\text { - Two patients: } \\
\text { topical I\%, } 2 \% \\
\text { ruxolitinib (BID) } \\
\text { - Four patients: } \\
\text { topical } 2 \% \text { tofacitinib } \\
\text { (BID) }\end{array}$ & $\begin{array}{l}\text { - One patient showed no } \\
\text { response } \\
\text { - One patient } \\
\text { experienced } 75 \% \\
\text { regrowth of only upper } \\
\text { eyelashes; no regrowth } \\
\text { of eyebrows } \\
\text { (only data from ruxolitinib- } \\
\text { treated patients) }\end{array}$ & $\begin{array}{l}\text { - } \\
\text { (only data from ruxolitinib- } \\
\text { treated patients) }\end{array}$ \\
\hline $\begin{array}{l}6 \text { Vandiver } \\
\text { et } \mathrm{al}^{71}\end{array}$ & 2017 & Case series & 2 & Alopecia areata & $\begin{array}{l}\text { Oral ruxolitinib } \\
\text { (10-30 mg daily) }\end{array}$ & $\begin{array}{l}\text { - One patient had } \\
\text { complete regrowth in } \\
8 \text { months } \\
\text { - One patient had near- } \\
\text { complete regrowth in } \\
6 \text { months }\end{array}$ & $\begin{array}{l}\text { - Five-pound weight gain } \\
\text { (I) } \\
\text { - Bloating and bruising (I) }\end{array}$ \\
\hline $\begin{array}{l}7 \text { Deeb and } \\
\text { Beach }^{72}\end{array}$ & 2017 & Case report & I & Alopecia areata & $\begin{array}{l}\text { Topical } 0.6 \% \\
\text { ruxolitinib (BID) }\end{array}$ & $\begin{array}{l}\text { - Patient showed no } \\
\text { improvement }\end{array}$ & - \\
\hline $\begin{array}{l}8 \text { Ramot and } \\
\text { Zlotogorski }^{73}\end{array}$ & 2018 & Case report & I & Alopecia universalis & $\begin{array}{l}\text { Oral ruxolitinib ( } 20 \mathrm{mg} \\
\text { BID) }\end{array}$ & $\begin{array}{l}\text { Patient had full regrowth } \\
\text { of beard and } 50 \% \\
\text { regrowth of scalp hair }\end{array}$ & - \\
\hline 9 Jabbari et $\mathrm{al}^{77}$ & 2015 & Case report & I & $\begin{array}{l}\text { Alopecia areata } \\
\text { and CANDLE } \\
\text { syndrome }\end{array}$ & $\begin{array}{l}\text { Oral baricitinib }(7 \mathrm{mg} \\
\text { morning and } 4 \mathrm{mg} \\
\text { evening) }\end{array}$ & $\begin{array}{l}\text { - Patient had full } \\
\text { regrowth in } 9 \text { months }\end{array}$ & - \\
\hline
\end{tabular}

Abbreviations: AA, alopecia areata; BID, bis in die (twice daily); CANDLE, chronic atypical neutrophilic dermatosis with lipodystrophy and elevated temperature; GI, gastrointestinal; JAK, janus kinase; URI, upper respiratory tract infection; UTI, urinary tract infection.

is $\mathrm{C}_{16} \mathrm{H}_{17} \mathrm{~N}_{7} \mathrm{O}_{2} \mathrm{~S}$ (Figure 5). ${ }^{75}$ In cell-based assays relevant to autoimmune diseases, baricitinib has been shown to inhibit JAK signaling and function initiated by IL- 6 and IL-23. ${ }^{76}$ Anti-inflammatory effects have also been observed in a mouse model with reduced CD8 infiltration and reduced MHC class I and class II expression when compared with vehicle control-treated mice. ${ }^{77}$
There has only been one case report concerning the efficacy of baricitinib in AA (Table 2). ${ }^{77}$ In 2015, Jabbari et al reported a patient with chronic atypical neutrophilic dermatosis with lipodystrophy and elevated temperature syndrome (CANDLE syndrome) and AA who was treated with oral baricitinib $7 \mathrm{mg}$ in the morning and $4 \mathrm{mg}$ in the evening. ${ }^{77}$ Complete regrowth of scalp hair was observed after 9 months of treatment. 


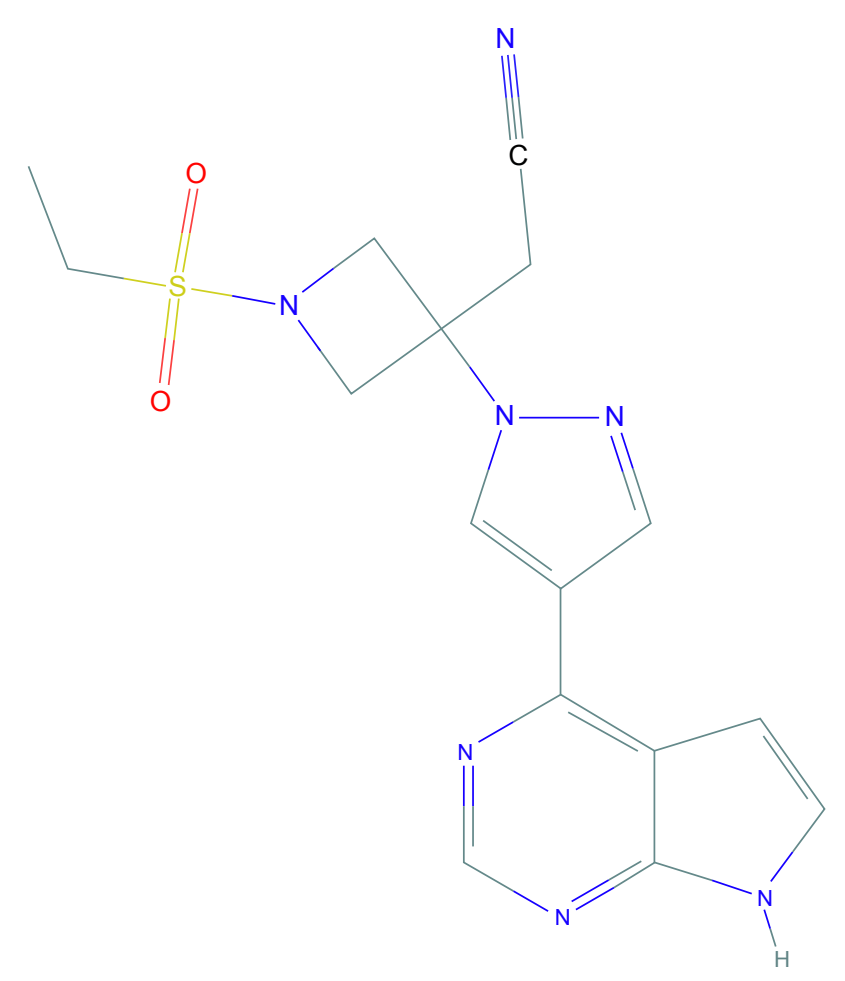

Figure 5 Baricitinib.

With regard to safety, Jabbari et al did not report any adverse events following baricitinib use in AA. ${ }^{77}$ A study on baricitinib in healthy volunteers showed no serious adverse events. Reported adverse events were neutropenia and reduced reticulocyte count. ${ }^{78}$ Baricitinib was considered to be noncarcinogenic based on the study of carcinogenicity assessment of baricitinib in mice. ${ }^{79}$

\section{Future directions}

Despite exceptional results in mice, ${ }^{10}$ researchers are still unable to reproduce similar efficacy of the topical preparation of tofacitinib and ruxolitinib in humans. Bayart et al demonstrated that a patient, who initially did not respond to the treatment, attained $95 \%$ hair growth after switching from tofacitinib in VersaBase ${ }^{\circledR}$ cream formulation to liposomal base formulation. ${ }^{50}$ This suggests that there is still room for improvement for topical JAKis especially in terms of pharmacokinetics and pharmacodynamics. In fact, researchers have already begun investigating into nanotechnology in the hope of better drug delivery, which might greatly enhance topical JAKi efficacy. ${ }^{80}$

Second-generation JAKis, equipped with a better selectivity of JAK receptor, are currently being studied in RA. Filgotinib (GLPG0634/GS-6034) and ABT-494, selective inhibitors of JAK1, and decernotinib (VX-509), a selective inhibitor of JAK3, have shown promising efficacy in Phase II studies of rheumatoid arthritis. ${ }^{81-83}$ WYE-151650, a selective inhibitor of JAK3, has been shown to have exceptional efficacy in collagen-induced arthritis in mice. ${ }^{84}$ These second-generation JAKis might be applicable in AA with similar efficacy and less toxicity and side effects. Future studies are needed to shed more light on the safety and efficacy of these new members of the JAKi family.

As previously mentioned, JAKis have many explained and unexplained roles in hair growth cycle regulation in addition to their anti-inflammatory effects. Several studies regarding their mechanism on hair growth cycle are ongoing. The implementation of JAKis in hair loss disorders, including scarring and nonscarring alopecia, other than AA may also be possible and should be investigated. In the near future, JAKis may become one of the effective treatment options for various hair loss disorders.

\section{Conclusion}

In recent years, safety and efficacy of various JAKis have been demonstrated in previous trials of RA, myelofibrosis, and various autoimmune and hematologic diseases. Currently, there is yet to be an FDA-approved JAKi for dermatologic indication. However, based on greater knowledge in the pathogenesis of AA and molecular biochemistry, JAKis are emerging as a promising treatment for AA. In this group, tofacitinib, ruxolitinib, and baricitinib have been studied in AA and its variants with varying outcomes. These studies demonstrated exceptional efficacy of oral tofacitinib and ruxolitinib in severe AA or refractory AA but unfavorable efficacy for topical preparation. Many case reports also showed promising results of oral tofacitinib and ruxolitinib in recalcitrant cases. Furthermore, side effects of tofacitinib and ruxolitinib demonstrated in AA cases were mostly transient and nonsevere. These data suggest that JAKis could be a great addition to the dermatologist's armament for tackling AA and a possible alternative in cases unresponsive to standard treatments. However, current evidence is based on case reports and uncontrolled trials. Well-controlled prospective studies are needed to determine long-term efficacy, safety, and cost-effectiveness, as well as to elucidate undisclosed mechanisms responsible for hair growth. As for baricitinib, available data are too sparse to conclude its efficacy and safety in AA. Further studies are needed for better understanding of baricitinib. Although JAKis are effective in various diseases, they, so far, have not been shown to provide long-term efficacy after stopping treatment in these diseases. Thus, JAKis might be more suitable for diseases with short duration or that are self-limited. Finally, from current evidence, JAKis are considered breakthrough treatment for AA. 


\section{Disclosure}

The authors report no conflicts of interest in this work.

\section{References}

1. Islam N, Leung PS, Huntley AC, Gershwin ME. The autoimmune basis of alopecia areata: a comprehensive review. Autoimmun Rev. 2015; 14(2):81-89.

2. Huang KP, Mullangi S, Guo Y, Qureshi AA, Autoimmune QAA. Autoimmune, atopic, and mental health comorbid conditions associated with alopecia areata in the United States. JAMA Dermatol. 2013; 149(7):789-794.

3. Chu SY, Chen YJ, Tseng WC, et al. Comorbidity profiles among patients with alopecia areata: the importance of onset age, a nationwide population-based study. J Am Acad Dermatol. 2011;65(5):949-956.

4. Lee NR, Kim BK, Yoon NY, Lee SY, Ahn SY, Lee WS. Differences in comorbidity profiles between early-onset and late-onset alopecia areata patients: a retrospective study of 871 Korean patients. Ann Dermatol. 2014;26(6):722-726

5. Muller SA, Winkelmann RK. Alopecia areata. An evaluation of 736 patients. Arch Dermatol. 1963;88:290-297.

6. de Weert J, Temmerman L, Kint A. Alopecia areata: a clinical study. Dermatologica. 1984;168(5):224-229.

7. Martinez-Mir A, Zlotogorski A, Gordon D, et al. Genomewide scan for linkage reveals evidence of several susceptibility loci for alopecia areata. Am J Hum Genet. 2007;80(2):316-328.

8. Colombe BW, Price VH, Khoury EL, Garovoy MR, Lou CD. HLA class II antigen associations help to define two types of alopecia areata. J Am Acad Dermatol. 1995;33(5 Pt 1):757-764.

9. Paus R, Ito N, Takigawa M, Ito T. The hair follicle and immune privilege. J Investig Dermatol Symp Proc. 2003;8(2):188-194.

10. Xing L, Dai Z, Jabbari A, et al. Alopecia areata is driven by cytotoxic T lymphocytes and is reversed by JAK inhibition. Nat Med. 2014;20(9):1043-1049.

11. Ito T, Ito N, Saatoff M, et al. Maintenance of hair follicle immune privilege is linked to prevention of NK cell attack. J Invest Dermatol. 2008; 128(5):1196-1206.

12. Petukhova L, Duvic M, Hordinsky M, et al. Genome-wide association study in alopecia areata implicates both innate and adaptive immunity. Nature. 2010;466(7302):113-117.

13. Betz RC, Petukhova L, Ripke S, et al. Genome-wide meta-analysis in alopecia areata resolves HLA associations and reveals two new susceptibility loci. Nat Commun. 2015;6:5966.

14. Paus R, Bertolini M. The role of hair follicle immune privilege collapse in alopecia areata: status and perspectives. J Investig Dermatol Symp Proc. 2013;16(1):S25-S27.

15. Sperling LC, Lupton GP. Histopathology of non-scarring alopecia. J Cutan Pathol. 1995;22(2):97-114

16. Ito T, Ito N, Saathoff M, Bettermann A, Takigawa M, Paus R. Interferongamma is a potent inducer of catagen-like changes in cultured human anagen hair follicles. Br J Dermatol. 2005;152(4):623-631.

17. Velazquez L, Fellous M, Stark GR, Pellegrini S. A protein tyrosine kinase in the interferon alpha/beta signaling pathway. Cell. 1992;70(2):313-322.

18. Darnell JE. STATs and gene regulation. Science. 1997;277(5332): 1630-1635.

19. Darnell JE, Kerr IM, Stark GR. Jak-STAT pathways and transcriptional activation in response to IFNs and other extracellular signaling proteins. Science. 1994;264(5164):1415-1421.

20. O'Shea JJ, Gadina M, Schreiber RD. Cytokine signaling in 2002 : new surprises in the Jak/Stat pathway. Cell. 2002;(109 Suppl): S121-S131.

21. Baxter EJ, Scott LM, Campbell PJ, et al. Acquired mutation of the tyrosine kinase JAK2 in human myeloproliferative disorders. Lancet. 2005;365(9464):1054-1061.

22. Macchi P, Villa A, Giliani S, et al. Mutations of Jak-3 gene in patients with autosomal severe combined immune deficiency (SCID). Nature. 1995;377(6544):65-68.
23. Harel S, Higgins CA, Cerise JE, et al. Pharmacologic inhibition of JAK-STAT signaling promotes hair growth. Sci Adv. 2015;1(9): e1500973.

24. Turksen K, Kupper T, Degenstein L, Williams I, Fuchs E. Interleukin 6: insights to its function in skin by overexpression in transgenic mice. Proc Natl Acad Sci U S A. 1992;89(11):5068-5072.

25. Kwack MH, Ahn JS, Kim MK, Kim JC, Sung YK. Dihydrotestosteroneinducible IL-6 inhibits elongation of human hair shafts by suppressing matrix cell proliferation and promotes regression of hair follicles in mice. J Invest Dermatol. 2012;132(1):43-49.

26. Yu M, Kissling S, Freyschmidt-Paul P, Hoffmann R, Shapiro J, Mcelwee KJ. Interleukin-6 cytokine family member oncostatin M is a hair-follicle-expressed factor with hair growth inhibitory properties. Exp Dermatol. 2008;17(1):12-19.

27. Meephansan J, Thummakriengkrai J, Ponnikorn S, Yingmema W, Deenonpoe R, Suchonwanit P. Efficacy of topical tofacitinib in promoting hair growth in non-scarring alopecia: possible mechanism via VEGF induction. Arch Dermatol Res. 2017;309(9):729-738.

28. Dhillon S. Tofacitinib: a review in rheumatoid arthritis. Drugs. 2017 ; 77(18):1987-2001.

29. Kuo CM, Tung TH, Wang SH, Chi CC. Efficacy and safety of tofacitinib for moderate-to-severe plaque psoriasis: a systematic review and meta-analysis of randomized controlled trials. J Eur Acad Dermatol Venereol. 2018;32(3):355-362.

30. Bose P, Verstovsek S. JAK2 inhibitors for myeloproliferative neoplasms: what is next? Blood. 2017;130(2):115-125

31. Alves de Medeiros AK, Speeckaert R, Desmet E, van Gele M, de Schepper S, Lambert J. JAK3 as an emerging target for topical treatment of inflammatory skin diseases. PLoS One. 2016;11(10): e0164080

32. Divito SJ, Kupper TS. Inhibiting Janus kinases to treat alopecia areata. Nat Med. 2014;20(9):989-990.

33. O’Shea JJ, Kontzias A, Yamaoka K, Tanaka Y, Laurence A. Janus kinase inhibitors in autoimmune diseases. Ann Rheum Dis. 2013; 72(Suppl 2):ii111-ii115.

34. National Center for Biotechnology Information. PubChem Compond Database: CID=9926791 [updated 2018 Mar 31; cited 2018 Apr 3]. Available from: https://pubchem.ncbi.nlm.nih.gov/compound/9926791. Accessed April 3, 2018.

35. Meyer DM, Jesson MI, Li X, et al. Anti-inflammatory activity and neutrophil reductions mediated by the JAK1/JAK3 inhibitor, CP-690,550, in rat adjuvant-induced arthritis. J Inflamm. 2010;7:41.

36. Ghoreschi K, Jesson MI, Li X, et al. Modulation of innate and adaptive immune responses by tofacitinib (CP-690,550). J Immunol. 2011;186(7):4234-4243.

37. Craiglow BG, King BA. Killing two birds with one stone: oral tofacitinib reverses alopecia universalis in a patient with plaque psoriasis. J Invest Dermatol. 2014;134(12):2988-2990.

38. Kennedy Crispin M, Ko JM, Craiglow BG, et al. Safety and efficacy of the JAK inhibitor tofacitinib citrate in patients with alopecia areata. JCI Insight. 2016;1(15):e89776.

39. Liu LY, Craiglow BG, Dai F, King BA. Tofacitinib for the treatment of severe alopecia areata and variants: A study of 90 patients. $\mathrm{J} \mathrm{Am} \mathrm{Acad}$ Dermatol. 2017;76(1):22-28.

40. Gupta AK, Carviel JL, Abramovits W. Efficacy of tofacitinib in treatment of alopecia universalis in two patients. J Eur Acad Dermatol Venereol. 2016;30(8):1373-1378.

41. Dhayalan A, King BA. Tofacitinib citrate for the treatment of nail dystrophy associated with alopecia universalis. JAMA Dermatol. 2016; 152(4):492-493.

42. Anzengruber F, Maul JT, Kamarachev J, Trüeb RM, French LE, Navarini AA. Transient efficacy of tofacitinib in alopecia areata universalis. Case Rep Dermatol. 2016;8(1):102-106.

43. Ferreira SB, Scheinberg M, Steiner D, Steiner T, Bedin GL, Ferreira RB. Remarkable improvement of nail changes in alopecia areata universalis with 10 months of treatment with tofacitinib: a case report. Case Rep Dermatol. 2016;8(3):262-266. 
44. Jabbari A, Nguyen N, Cerise JE, et al. Treatment of an alopecia areata patient with tofacitinib results in regrowth of hair and changes in serum and skin biomarkers. Exp Dermatol. 2016;25(8):642-643.

45. Mrowietz U, Gerdes S, Gläser R, Schröder O. Successful treatment of refractory alopecia areata universalis and psoriatic arthritis, but not of plaque psoriasis with tofacitinib in a young woman. Acta Derm Venereol. 2017;97(2):283-284.

46. Liu LY, Craiglow BG, King BA. Tofacitinib 2\% ointment, a topical Janus kinase inhibitor, for the treatment of alopecia areata: A pilot study of 10 patients. J Am Acad Dermatol. 2018;78(2):403-404.

47. Craiglow BG, Liu LY, King BA. Tofacitinib for the treatment of alopecia areata and variants in adolescents. J Am Acad Dermatol. 2017; 76(1):29-32.

48. Ibrahim O, Bayart CB, Hogan S, Piliang M, Bergfeld WF. Treatment of alopecia areata with tofacitinib. JAMA Dermatol. 2017; 153(6):600-602.

49. Park HS, Kim MW, Lee JS, et al. Oral tofacitinib monotherapy in Korean patients with refractory moderate-to-severe alopecia areata: A case series. J Am Acad Dermatol. 2017;77(5):978-980.

50. Bayart CB, Deniro KL, Brichta L, Craiglow BG, Sidbury R. Topical janus kinase inhibitors for the treatment of pediatric alopecia areata. J Am Acad Dermatol. 2017;77(1):167-170.

51. Castelo-Soccio L. Experience with oral tofacitinib in 8 adolescent patients with alopecia universalis. J Am Acad Dermatol. 2017;76(4): 754-755.

52. Scheinberg M, de Lucena Couto Ocea RA, Cruz BA, Ferreira SB. Brazilian experience of the treatment of alopecia universalis with the novel antirheumatic therapy tofacitinib: a case series. Rheumatol Ther. 2017; 4(2):503-508.

53. Kim BY, Kim HS. Successful hair regrowth in a Korean patient with alopecia universalis following tofacitinib treatment. Singapore Med J. 2017;58(5):279-280.

54. Strazzulla LC, Avila L, Lo Sicco K, Shapiro J. Image Gallery: Treatment of refractory alopecia universalis with oral tofacitinib citrate and adjunct intralesional triamcinolone injections. $\mathrm{Br} J$ Dermatol. 2017;176(6):e125.

55. Erduran F, Adışen E, Aksakal AB. Excellent response to tofacitinib treatment in a patient with alopecia universalis. Acta Dermatovenerol Alp Pannonica Adriat. 2017;26(2):47-49.

56. Salman A, Sarac G, Ergun T. Alopecia universalis unresponsive to treatment with tofacinitib: report of a case with a brief review of the literature. Dermatol Online J. 2017;23(7):13030/qt224878kb.

57. Jabbari A, Sansaricq F, Cerise J, et al. An open-label pilot study to evaluate the efficacy of tofacitinib in moderate to severe patch-type alopecia areata, totalis, and universalis. J Invest Dermatol. 2018;138(7): 1539-1545

58. Patel NU, Oussedik E, Grammenos A, Pichardo-Geisinger R. A case report highlighting the effective treatment of alopecia universalis with tofacitinib in an adolescent and adult patient. J Cutan Med Surg. 2018;22(4):439-442.

59. XELJANZ ${ }^{\circledR} / X$ ELJANZ XR ${ }^{\circledR}$ (tofacitinib) tablets, film coated, extended release [pescribing information]. New York: Pfizer Laboratories Div Pfizer Inc. 2012; Available from: http://labeling.pfizer.com/ShowLabeling.aspx?id=959. Accessed April 3, 2018

60. Curtis JR, Lee EB, Kaplan IV, et al. Tofacitinib, an oral Janus kinase inhibitor: analysis of malignancies across the rheumatoid arthritis clinical development programme. Ann Rheum Dis. 2016;75(5): 831-841.

61. National Center for Biotechnology Information. PubChem Compound Database; $\mathrm{CID}=25126798$ [updated 2018 Mar 31; cited 2018 Apr 3]; 2018. Available from: https://pubchem.ncbi.nlm.nih.gov/ compound/25126798. Accessed April 3, 2018.

62. Verstovsek S, Kantarjian H, Mesa RA, et al. Safety and efficacy of INCB018424, a JAK1 and JAK2 inhibitor, in myelofibrosis. $N$ Engl $J$ Med. 2010;363(12):1117-1127.

63. Harrison C, Kiladjian JJ, Al-Ali HK, et al. JAK inhibition with ruxolitinib versus best available therapy for myelofibrosis. $N$ Engl J Med. 2012;366(9):787-798.
64. Quintás-Cardama A, Vaddi K, Liu P, et al. Preclinical characterization of the selective JAK1/2 inhibitor INCB018424: therapeutic implications for the treatment of myeloproliferative neoplasms. Blood. 2010; 115(15):3109-3117.

65. Punwani N, Scherle P, Flores R, et al. Preliminary clinical activity of a topical JAK1/2 inhibitor in the treatment of psoriasis. $\mathrm{J} \mathrm{Am} \mathrm{Acad}$ Dermatol. 2012;67(4):658-664.

66. Jakafi $^{\circledR}$ (ruxolitinib) tablets [prescribing information]. Delaware: Incyte Corporation. 2011. Available from: http://www.jakafi.com/pdf/ prescribing-information.pdf. Accessed April 3, 2018.

67. Song J, Song A, Palmares T, Song M, Song H. Ruxolitinib found to cause eyelash growth: a case report. J Med Case Rep. 2017;11(1):189.

68. Pieri L, Guglielmelli P, Vannucchi AM. Ruxolitinib-induced reversal of alopecia universalis in a patient with essential thrombocythemia. $\mathrm{Am}$ J Hematol. 2015;90(1):82-83.

69. Craiglow BG, Tavares D, King BA. Topical ruxolitinib for the treatment of alopecia universalis. JAMA Dermatol. 2016;152(4):490-491.

70. Mackay-Wiggan J, Jabbari A, Nguyen N, et al. Oral ruxolitinib induces hair regrowth in patients with moderate-to-severe alopecia areata. JCI Insight. 2016;1(15):e89790.

71. Vandiver A, Girardi N, Alhariri J, Garza LA. Two cases of alopecia areata treated with ruxolitinib: a discussion of ideal dosing and laboratory monitoring. Int J Dermatol. 2017;56(8):833-835.

72. Deeb M, Beach RA. A case of topical ruxolitinib treatment failure in alopecia areata. J Cutan Med Surg. 2017;21(6):562-563.

73. Ramot Y, Zlotogorski A. Complete regrowth of beard hair with ruxolitinib in an alopecia universalis patient. Skin Appendage Disord. 2018;4(2):122-124.

74. Galli S, Mclornan D, Harrison C. Safety evaluation of ruxolitinib for treating myelofibrosis. Expert Opin Drug Saf. 2014;13(7):967-976.

75. National Center for Biotechnology Information. NationalCenter for Biotechnology Information. PubChem Compound Database; $\mathrm{CID}=44205240$ [updated 2018 Mar 31; cited 2018 Apr 3]. Available from: https://pubchem.ncbi.nlm.nih.gov/compound/44205240. Accessed April 3, 2018.

76. Fridman JS, Scherle PA, Collins R, et al. Selective inhibition of JAK1 and JAK2 is efficacious in rodent models of arthritis: preclinical characterization of INCB028050. J Immunol. 2010;184(9):5298-5307.

77. Jabbari A, Dai Z, Xing L, et al. Reversal of alopecia areata following treatment with the JAK1/2 inhibitor baricitinib. EBioMedicine. 2015;2(4):351-355.

78. Shi JG, Chen X, Mcgee RF, et al. The pharmacokinetics, pharmacodynamics, and safety of orally dosed INCB018424 phosphate in healthy volunteers. J Clin Pharmacol. 2011;51(12):1644-1654.

79. Carfagna M, Cannady E, Ryan T, et al. Carcinogenicity assessment of baricitinib in Tg.rasH2 mice and Sprague-Dawley (Crl:CD) rats. Regul Toxicol Pharmacol. 2018;92:458-471.

80. Boca S, Berce C, Jurj A, et al. Ruxolitinib-conjugated gold nanoparticles for topical administration: An alternative for treating alopecia? Med Hypotheses. 2017;109:42-45.

81. Vanhoutte F, Mazur M, Voloshyn O, et al. Efficacy, safety, pharmacokinetics, and pharmacodynamics of filgotinib, a selective JAK-1 inhibitor, after short-term treatment of rheumatoid arthritis: results of two randomized phase IIa trials. Arthritis Rheumatol. 2017;69(10):1949-1959.

82. Genovese MC, Smolen JS, Weinblatt ME, et al. Efficacy and safety of ABT-494, a selective JAK-1 inhibitor, in a phase IIb study in patients with rheumatoid arthritis and an inadequate response to methotrexate. Arthritis Rheumatol. 2016;68(12):2857-2866.

83. Genovese MC, van Vollenhoven RF, Pacheco-Tena C, Zhang Y, Kinnman N. VX-509 (Decernotinib), an oral selective JAK-3 inhibitor, in combination with methotrexate in patients with rheumatoid arthritis. Arthritis Rheumatol. 2016;68(1):46-55.

84. Lin TH, Hegen M, Quadros E, et al. Selective functional inhibition of JAK-3 is sufficient for efficacy in collagen-induced arthritis in mice. Arthritis Rheum. 2010;62(8):2283-2293. 


\section{Publish your work in this journal}

Drug Design, Development and Therapy is an international, peerreviewed open-access journal that spans the spectrum of drug design and development through to clinical applications. Clinical outcomes, patient safety, and programs for the development and effective, safe, and sustained use of medicines are the features of the journal, which has also been accepted for indexing on PubMed Central. The manuscript management system is completely online and includes a very quick and fair peer-review system, which is all easy to use. Visit http://www.dovepress.com/testimonials.php to read real quotes from published authors.

Submit your manuscript here: http://www.dovepress.com/drug-design-development-and-therapy-journal 